\title{
Cyclization of Cyclopropyl Carbonyls and the Homo-Nazarov Reaction
}

\author{
Filippo De Simone and Jérôme Waser*
}

\begin{abstract}
Ring strain confers exceptional reactivity to the cyclopropane ring. Nevertheless, activation of the cyclopropane ring is usually needed to allow ring-opening reactions under mild conditions. The introduction of one or several carbonyl functionalities on cyclopropanes is often used to enhance their electrophilic reactivity. When a donor group is also present at the vicinal position to the carbonyl, more reactive donor-acceptor systems are obtained, which are ideally suited for homo-conjugate addition or cycloaddition reactions. This short review focuses on the special case of intramolecular cyclization reactions. Particular emphasis is devoted to the cyclization of vinyl- and aryl-cyclopropyl ketones for the formation of six-membered rings. This process corresponds to a formal homo-Nazarov cyclization and has been only used rarely in the past. Recently, the scope of the reaction was greatly expanded by the use of a silyl group as cation-stabilizing group and by the first catalytic method for the synthesis of vinyl-cyclopropyl ketones. With these new developments, the basis is now set for the application of this special class of cationic cyclizations to the synthesis of more complex synthetic and natural products.
\end{abstract}

Keywords: Activated cyclopropanes · Carbocation · Catalysis · Cyclization · Polycyclic structures

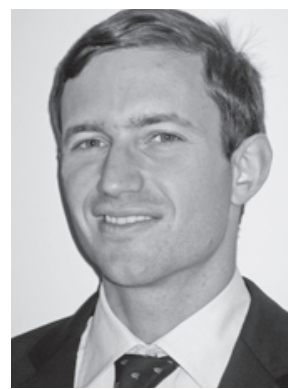

Jérôme Waser was born in Sierre, Valais, Switzerland in 1977. He studied chemistry at ETH Zürich and obtained his Diploma in 2001. In 2002, he started his $\mathrm{PhD}$ studies at ETH Zurich with Prof. Erick M. Carreira working on the development of metal-catalyzed amination reactions of olefins. In 2006, he joined Prof. Barry M. Trost at Stanford University and accomplished the total synthesis of Pseudolaric Acid B, a diterpene natural product.

Since October 2007, he is working as tenure-track assistant professor at EPF Lausanne, focusing on the development and application of catalytic methods for the synthesis of bioactive compounds.

${ }^{\star}$ Correspondence: Prof. Dr. J. Waser

Ecole Polytechnique Fédérale de Lausanne Laboratory of Catalysis and Organic Synthesis

EPFL SB ISIC LCSO

$\mathrm{CH}-1015$ Lausanne

Tel.: +41216939388

Fax: + 41216939700

E-mail: jerome.waser@epfl.ch
Small rings play a privileged role in organic chemistry. ${ }^{[1]}$ Due to ring strain, they can participate in several unique reactions which are not accessible to linear or larger cyclic molecules. The cyclopropane ring in particular has always fascinated both synthetic and theoretical chemists. ${ }^{[2]}$ It has been demonstrated to have a high $\pi$ character best described theoretically by the Walsh orbitals, ${ }^{[3]}$ which results in a reactivity somewhat similar to double bonds. For example, addition reactions to cyclopropane, insertion into metal-carbon bonds and stabilization of radical or cationic intermediates in the $\alpha$ position are well-established properties of cyclopropanes. ${ }^{[1,2]}$ Nevertheless, cyclopropane rings are rather stable, unless adequate substitution is introduced to polarize one of the $\mathrm{C}-\mathrm{C}$ bonds of the ring. The introduction of one or several carbonyl groups is one of the most straightforward ways to activate the cyclopropane ring. After the discovery of the homologous Michael addition by Bone and Perkin in $1895,{ }^{[4]}$ the use of activated cyclopropanes has constantly increased in organic chemistry. This goes together with tremendous progress in the synthesis of cyclopropanes, including asymmetric methods. ${ }^{[1,2]}$

The reactivity of cyclopropanes can be further increased by the introduction of an electron-donating substituent in the vicinal position to the carbonyl group. The so-called donor-acceptor cyclopropanes have been intensively used in organic chemistry. ${ }^{[5]}$ The most frequent activating groups are carbonyl groups as acceptors, and heteroatoms or electron-rich aromatic groups as donors. Donor-acceptor cyclopropyl carbonyls are versatile synthons in organic chemistry, which can be considered both as 1-3 dipoles and homologs of Michael acceptors (Scheme 1). After ring-opening, a center with cationic character is generated in the position $\gamma$ to the carbonyl, which constitutes an Umpolung of the normal reactivity and allows access to dissonant substitution patterns in the product (for example 1,4-dicarbonyls starting from cyclopropanols). ${ }^{6]}$ Consequently, donoracceptor cyclopropanes have been firmly established in the arsenal of classical organic chemistry. Their unique property to act as 1,3-dipoles for [3+2] and [3+3] cycloadditions in modern catalytic reactions has been fully recognized recently and several research groups have demonstrated their versatility in the efficient synthesis of cyclic compounds. ${ }^{[7]}$

Beside cycloaddition reactions, cyclization reactions involving the intramolecular addition of a nucleophile on acti-

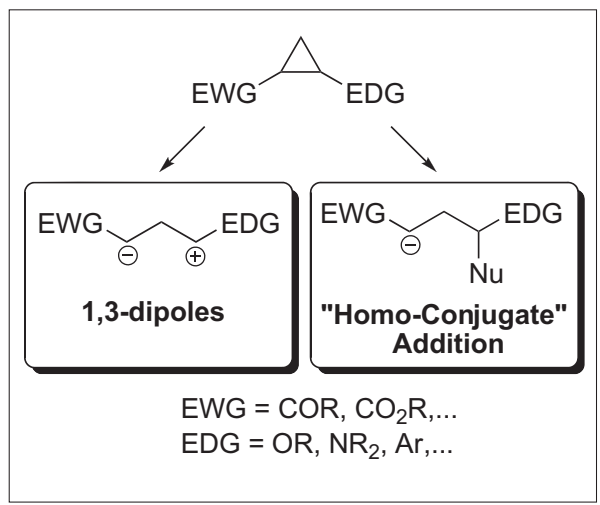

Scheme 1. Unique properties of donoracceptor cyclopropanes. 


\section{Stork and Marx 1969}<smiles>COc1cccc(CC[C@@H]2C3C(=O)CCC32C)c1</smiles>

Corey and Balanson 1973<smiles>CC(C)=CCCC(C)C12CCC(=O)C1C2</smiles><smiles>C[C@@H]1C(=O)CCC2(C)C1CC[C@@H]2C</smiles>

Danishefsky and Co-workers 1974

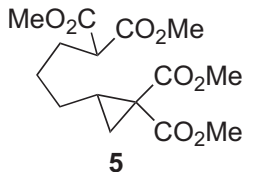
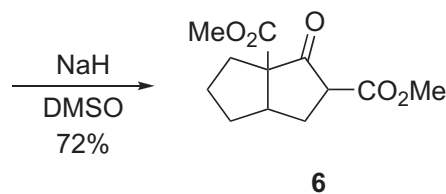

Scheme 2. Early work on cyclization reactions of activated cyclopropanes.

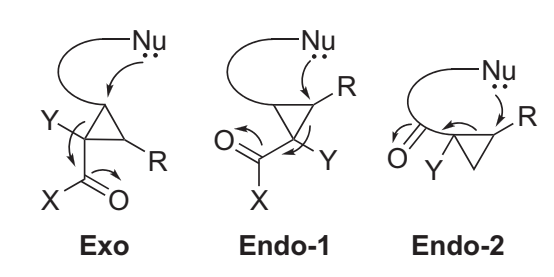

Fig. The three different modes of cyclization of activated cyclopropanes.

vated carbonyl cyclopropanes constitutes another interesting access to cyclic compounds and has been extensively examined by the groups of Stork, ${ }^{[8 \mathrm{a}-\mathrm{d}]}$ Corey[8e] and Danishefsky ${ }^{[8 \mathrm{f}]}$ among others ${ }^{[8 \mathrm{~g}, \mathrm{~h}]}$ in the 1960s and 1970s (Scheme 2). In principle, three modes of cyclization can be envisaged (Fig.): exo cyclization, with only one carbon atom of the cyclopropane ring incorporated in the newly formed cycle, endo cyclization with the carbonyl group(s) outside and two carbon atoms of the cyclopropane ring incorporated in the newly formed ring or a second endo process where all the carbon atoms of the cyclopropane ring are incorporated in the newly formed cycle. Detailed studies by Danishefsky have shown that the exomode of cyclization is usually favored with diester-activated cyclopropanes. ${ }^{[8 \mathrm{~h}]}$ Later, Smith and co-workers introduced a one-pot cyclopropanation-cyclization sequence. ${ }^{[9]}$ Surprisingly, intramolecular cyclizations on activated cyclopropanes have not been further developed following these preliminary studies, as recent research had more focused on intermolecular reactions using an external nucleophile. ${ }^{[10]}$

The endo-cyclization mode where all the atoms of the cyclopropane are incor- porated in the formed ring has been much less studied. From a stereoelectronic point of view, this pathway for cyclization is the most difficult, as adequate orbital alignment cannot be achieved for a synchronous transition state in smaller rings. Consequently, a stepwise process via a zwitterionic intermediate has to be followed, for example by going from simple acceptor-activated cyclopropanes to donor-acceptor systems. The case of vinyl-cyclopropyl ketones constitutes a particularly interesting case for endo cyclization. Indeed, if the partial $\pi$ character of the cyclopropane is taken into account, such cyclization corresponds to a homologous reaction of the well-known Nazarov cyclization of divinyl ketones (Scheme 3). The Nazarov reaction is a synchronous electrocyclic ring-closure of a pentadienyl cation and follows the Woodward-Hoffman's rules. Since its discovery in 1941, the Nazarov reaction has proven very useful in organic synthesis, but the use of a stoichiometric amount of strong Lewis or Brønsted acids has limited its use

$$
\text { Nazarov }
$$

Homo-Nazarov

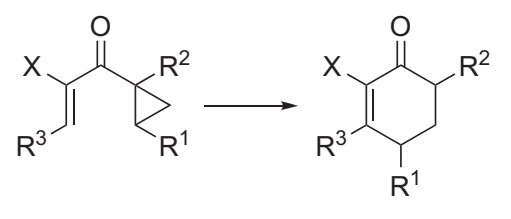

Scheme 3. Nazarov vs homo-Nazarov cyclization. for the synthesis of sensitive substrates.[11] Recently, however, mild catalytic methods have been developed for the Nazarov reaction, including the first example of asymmetric induction. ${ }^{[12]}$ During these studies, cross-polarized substrates bearing an oxygen atom $\alpha$ to the carbonyl ( $\mathrm{X}$ in Scheme 3 ) have emerged as exceptional substrates for the Nazarov cyclization. ${ }^{[12 h]}$ Inspired by this recent progress, we wondered if similar principles could be applied to vinyl-cyclopropyl ketones, which would constitute a formal homo-Nazarov reaction.

Before our own studies, reports on the cyclization of vinyl-cyclopropyl ketones were very rare (Scheme 4). Tsuge and coworkers studied the cyclization of vinylcyclopropyl ketones using a large excess of polyphosphoric acid in benzene under reflux. ${ }^{[13]}$ Several products were isolated depending on the substitution pattern of the cyclopropane and the vinyl group, but the scope was limited and the reaction was not further examined in detail. Furthermore, the harsh conditions used are not appropriate for sensitive substrates. The cyclization of the related aryl-cyclopropyl ketones has been more intensively investigated, ${ }^{[14]}$ especially by Murphy and Wattanasin, who developed the methodology for the synthesis of tetralone derivatives (Scheme 4). ${ }^{\text {14a-d] }}$ Their studies were limited to electron-rich benzene rings on the ketone and the cyclopropane, however. Nevertheless, careful mechanistic investigation showed that the mechanism was probably stepwise via a stabilized benzylic cation. Importantly, they were able to isolate dihydrofuran and alcohol as side products through trapping of the carbocation when electron-donating groups were absent on the benzene rings. These results showed that this kind of cyclization proceeds in a stepwise manner and is mechanistically different from the Nazarov cyclization. Unfortunately, the cyclizations were always run in the presence of an excess of strong Lewis acids, such as $\mathrm{SnCl}_{4}$, which is not compatible with sensitive substrates. In 2005, Otto and co-workers reported that heterocycles such as furan and thiophene could also be used in this cyclization reaction. ${ }^{[14 \mathrm{e}]}$ In 2008 , the scope of the reaction of aryl cyclopropyl ketones was greatly expanded by Yadav and Kumar by the use of a silyl group as cation-stabilizing substituent (Table 1).[14f] In the past years, the Yadav's group has established silyl groups as a versatile alternative to other classical donor substituents in donor-acceptor cyclopropanes and have documented their use in several reactions. ${ }^{[15]}$ Yadav and Kumar's method greatly expanded the scope of the formal homoNazarov cyclization and could be used for furan, thiophene and indole heterocycles substituted at position 2 or 3 (Table entries 1-4). The silyl group used to stabilize the 


\section{Tsuge and Co-workers 1988}<smiles>[R]C([R])=CC(=O)C1CC1c1ccccc1</smiles>

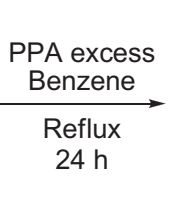<smiles>[R]C([R])=CC(=O)CCC(O)c1ccccc1</smiles><smiles>[R]C1([R])c2ccccc2C2CCC(=O)C21</smiles>

Murphy and Wattanasin 1980<smiles>[R]c1ccc(C2CC2C(=O)c2ccccc2)cc1</smiles><smiles>[R1]c1ccc2c(c1)C(c1ccccc1)CCC2=O</smiles><smiles>[R]c1ccc(C(O)(CCC(=O)c2ccccc2)c2ccccc2[R])cc1</smiles>

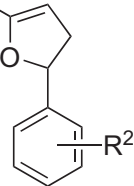

Scheme 4. Early work on the formal homo-Nazarov cyclization.

Table 1. Formal homo-Nazarov cyclization of activated cyclopropanes developed by Yadav and Kumar.

Entry Substrate

Product

Isolated Yield ${ }^{2}$

1
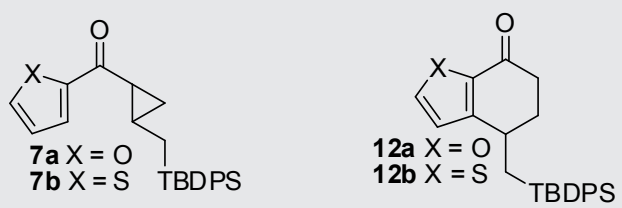

$80 \%(X=0)$

$80 \%(X=S)$
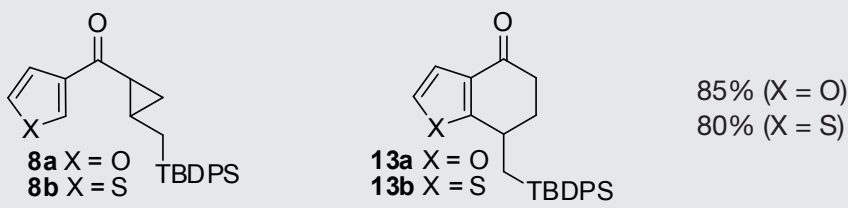

3
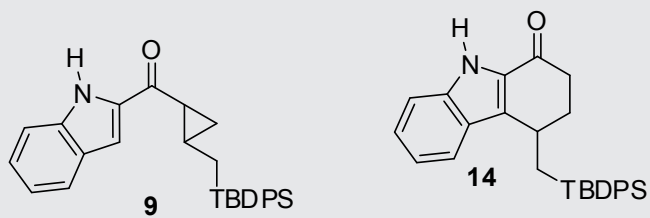

$85 \%$

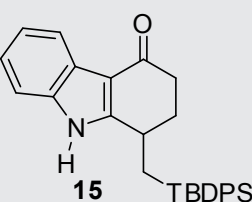

$80 \%$
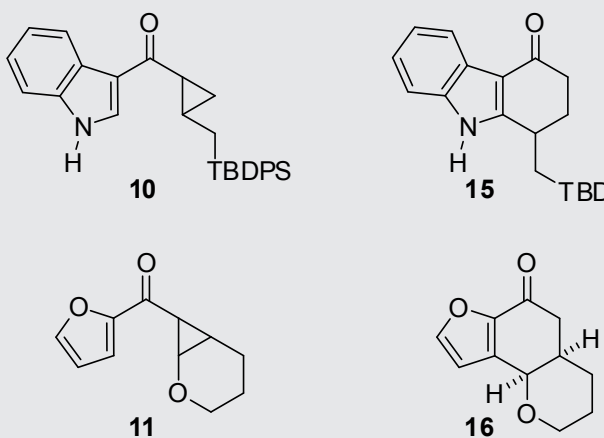

$65 \%$
In parallel to Yadav and Kumar's work, weinitiated our own studies in early 2008. ${ }^{[16]}$ Our first goal was to find a catalytic version of the formal homo-Nazarov reaction, as we were convinced that milder reaction conditions will greatly enhance the utility of the reaction in organic synthesis. Based on the mechanistic investigations of Murphy and Wattanasin, a stepwise process via carbocationic intermediates appeared probable. If adequate cation-stabilizing group were present on the vinyl cyclopropyl ketones, cyclization under mild catalytic conditions should be possible (Scheme 5).

Inspired by the known favorable effect of $\alpha$ heteroatoms in the Nazarov cyclization, ${ }^{[12 \mathrm{~h}]}$ pyran-derived substrate 17 was selected as a model substrate. Substrate 17 combines the successful donor-acceptor cyclopropanes used in Murphy and Wattanasin's work with an $\alpha$-heteroatom to stabilize a carbocation intermediate after cyclization and control the regioselectivity of the double bond formation. When substrate $\mathbf{1 7}$ was submitted to the reported reaction conditions with a strong Lewis acid like $\mathrm{SnCl}_{4},{ }^{[14]}$ a low yield of the desired cyclization product was observed, but polymerization was the main reaction pathway. Obviously, the reported conditions were not compatible with this class of more sensitive substrates. A rapid screen of diverse Lewis acids demonstrated that it was difficult to reach the right reactivity balance, as strong Lewis acids like $\mathrm{SnCl}_{4}, \mathrm{BF}_{3} \cdot \mathrm{OEt}_{2}$ or $\mathrm{Sc}(\mathrm{OTf})_{3}$ led to polymerization, even in catalytic amounts, and no reaction was observed with weaker Lewis acids like $\mathrm{Cu}(\mathrm{OTf})_{2}$. A promising result was observed with $\mathrm{AlCl}_{3}$, however, with $60 \%$ crude yield. Brønsted acids were

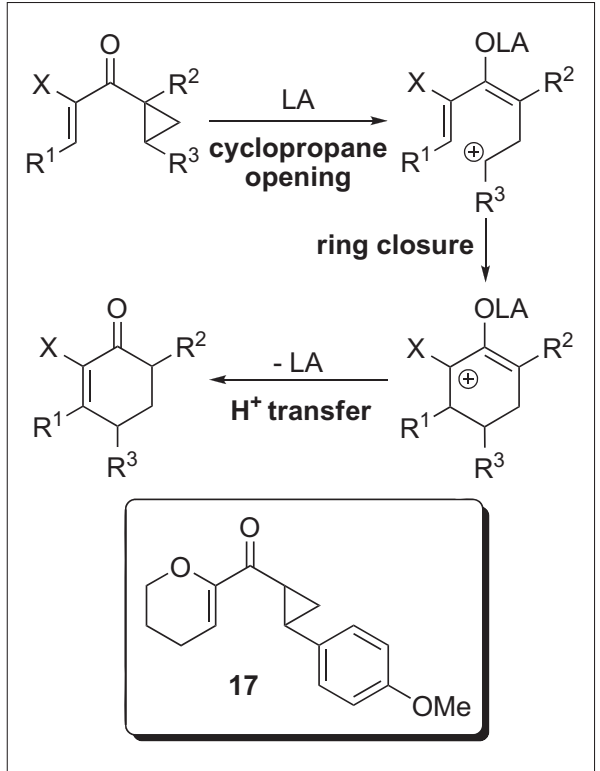

Scheme 5. Hypothetical mechanism and substrate design for a catalytic homo-Nazarov

cyclization. suited for further functional group manipulations. The first example of an oxygen heteroatom as donor group in the cycliza- tion reaction was also reported in this work (entry 5). Unfortunately, Yadav and Kumar still relied on harsh conditions (4 equiv. of $\mathrm{SnCl}_{4}$ in dichloroethane at $80^{\circ} \mathrm{C}$ ). 
examined next, as the $\mathrm{pK}_{\mathrm{a}}$ value of the acids allow an easy assessment of the acid strength. A sharp optimum was observed when using toluene sulfonic or sulfonic acids $\left(\mathrm{pK}_{\mathrm{a}}=-2\right)$, which led to complete conversion of the starting material. Stronger acids led to polymerization, whereas the reaction was too slow using weaker acids. A strong solvent effect on the reaction rate was also observed. Non-polar solvents such as dichloromethane or toluene led to a fast conversion, but polymerization was still occurring. In polar protic solvents, such as methanol, the reaction was very slow. Finally, the optimal solvent proved to be acetonitrile: the use of $20 \mathrm{~mol} \%$ toluene sulfonic acid in this solvent led to complete conversion to the desired cyclohexenone product overnight in $80 \%$ crude yield $(70 \%$ isolated yield, Table 2, entry 1).

To better assign the scope of the reaction, the electronic properties of the aromatic group on the cyclopropane ring were then modified (Table 2, entries 2-3). In accordance with a defined carbocationic intermediate, only electron-rich aromatic groups led to efficient cyclization. For example, no reaction was observed with a phenyl group (entry 2), whereas the reaction was more efficient with a second methoxy group on the aromatic ring (entry 3 ). This requirement for a very good electron donor is stronger than in the Nazarov reaction or in the exo cyclization of cyclopropyl ketones and suggests a stepwise mechanism. Interestingly, the introduction of a methyl group in $\alpha$ position to the ketone also led to an increase of efficiency and rate of the cyclization reaction (entry 4 ). This could be explained by a stronger release of steric strain on opening the cyclopropane ring and by the enhanced stability of the formed enol intermediate.

To further expand the scope of the reaction, the dihydropyran heterocycle was replaced by a dihydrofuran ring and several aromatic heterocycles (Table 2, entries 5-7). Interestingly, the reaction outcome was dependent on the exact structure of the heterocycle: Dihydrofuran (entry 5) and indole (entry 6) led to an efficient cyclization, but only polymerization was observed with benzofuran (entry 7 ), in contrast to the good yields observed using stoichiometric Lewis acids. Finally, the use of the unique properties of allyl silane as nucleophile allowed the first synthesis of a fused carbocycle under catalytic conditions (entry 8). As in the related work of Denmark for the Nazarov cyclization, [17] complete regioselectivity was observed for double bond formation via elimination of the silyl group. The reaction appeared to be highly stereoselective, as only one diastereoisomer of the product was observed.

The observed scope of the reaction and the strong dependence on the $\mathrm{pK}_{\mathrm{a}}$ of
Table 2. Catalytic formal homo-Nazarov cyclization of vinyl and aryl cyclopropyl ketones.

Entry Substrate Product Isolated Yielda<smiles>COc1ccc(C2CC2C(=O)C2=CCCCO2)cc1</smiles><smiles>COc1ccc(C2CCC(=O)C3=C2CCCO3)cc1</smiles>

$70 \%$

2<smiles>O=C(C1=CCCCO1)C1CC1c1ccccc1</smiles>

no reaction<smiles>COc1ccc(C2CC2C(=O)C2=CCCCO2)cc1OC</smiles><smiles>COc1ccc(C2CCC(=O)C3=C2CCCO3)cc1OC</smiles><smiles></smiles><smiles>CCCOc1ccc(C2CC(C)C(=O)C3=C2CCCO3)cc1</smiles><smiles>COc1ccc(C2CC2C(=O)C2=CCCO2)c(OC)c1</smiles><smiles>COc1ccc(C2CCC(=O)C3=C2CCO3)c(OC)c1</smiles>

$>95 \%$<smiles>COc1ccc(C2CC2C(=O)c2cc3ccccc3n2C)cc1</smiles><smiles>COc1ccc(C2CCC(=O)c3c2c2ccccc2n3C)cc1</smiles>

$>95 \%$

polymerization
8<smiles>COc1ccc(C2CC2C(=O)c2cc3ccccc3o2)cc1</smiles>

7<smiles>COc1ccc(C2CC2C(=O)C2=CCCCC2C)c(OC)c1</smiles><smiles>COc1ccc(C2CCC(=O)C3=CCCC[C@@H]32)c(OC)c1</smiles> 
the Brønsted acid catalysts were strong evidence for a stepwise process via carbocationic intermediates. Nevertheless, it appeared very important to examine more carefully the mechanism of the reaction to allow further development of the method. At first, the kinetics of the reaction was carefully examined. The reaction was shown to have a first order dependence on the concentration of the catalyst. Together with the strong effect of electron-rich substituent on the cyclopropane, this suggests that the rate-limiting transition state involves the acid catalyst in a ring-opening process. To better understand the proton transfer step in the cyclization, the reaction was then done in the presence of one equivalent of deuterated toluene sulfonic acid (Scheme 6). From the outset, two main outcomes were expected: no incorporation of deuterium if an internal proton transfer was favored or a mixture of nondeuterated and mono-deuterated products if the proton was transferred via the acid. Indeed, both non-deuterated and monodeuterated products were observed. More surprisingly, bis-deuterated product 32 was also obtained. As a control experiment showed that proton-deuterium exchange was not possible on the cyclohexenone product under the reaction conditions, this indicated that proton-deuterium exchange was faster on one of the intermediates of the catalytic cycle and required us to refine our proposed mechanism (Scheme 7). One could argue that the vicinity of the positive charge enhances the acidity of the proton in intermediate IIa. Another explanation would be an intramolecular attack of the oxygen atom of the ketone to form oxonium IIIa, which would greatly enhance the acidity of the $\alpha$ proton and allow a fast exchange via dihydrofuran intermediate IIIb.

In order to further prove the intermediacy of the proposed cationic intermediates, the reaction was run in the presence of water and other trapping agents. In the case of standard dihydropyran substrate 17, no other products than the normal cyclohexenone were observed, which further indicates that the steps following the opening of the cyclopropane ring are very fast. To slow down the key cyclization event, cyclohexene-derived substrate $\mathbf{3 3}$ was synthesized (Scheme 6). Under standard reaction conditions, no cyclized product was observed, although the conversion of the starting material was complete in a time frame similar to $\mathbf{1 7}$. In this case, only polymeric products were obtained. However, when the reaction was run in the presence of water ( $5 \mathrm{vol} \%), 32 \%$ yield of the corresponding alcohol 34 was isolated, confirming the intermediacy of a carbocationic intermediate. These preliminary results gave a first crude idea of the reaction mecha-

\section{Deuterium Labeling}<smiles>[2H]C1([2H])CC(c2ccc(OC)cc2)C2=C(OCCC2)C1=O</smiles>

$25: 31: 32=0.9: 1: 0.7$

Trapping Experiment
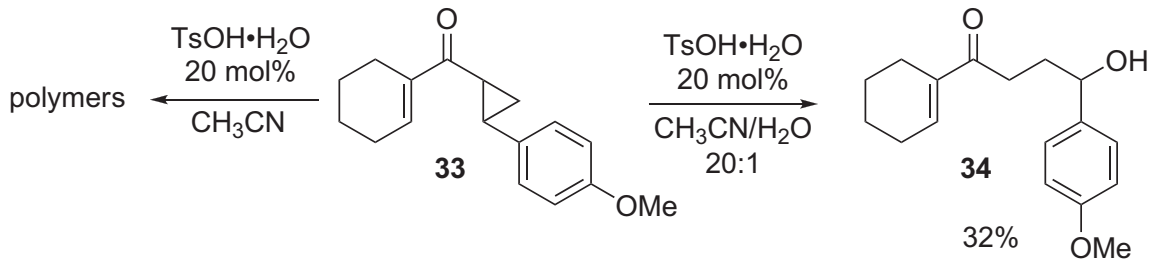

Scheme 6. Key experiments for mechanism elucidation.

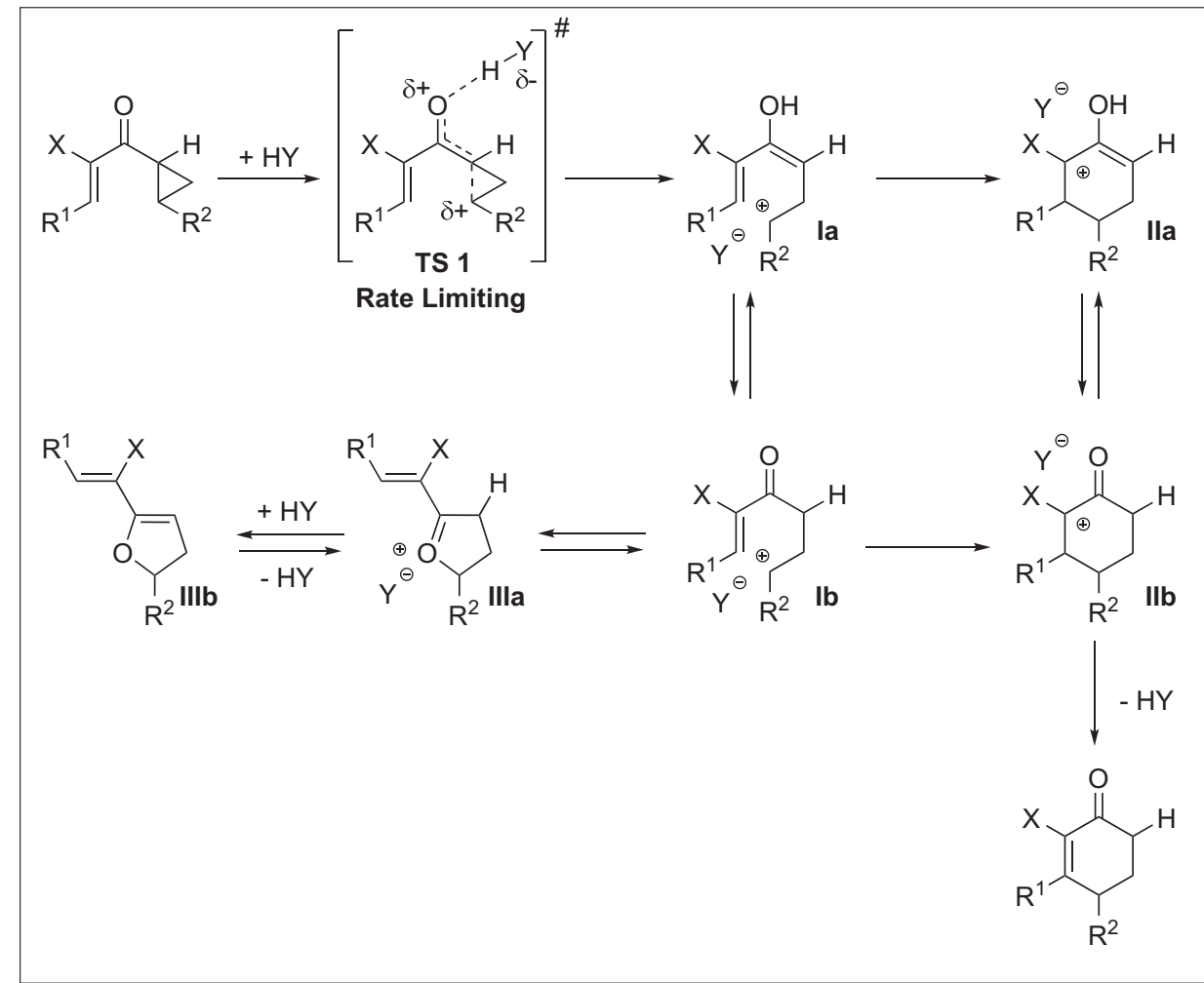

Scheme 7. Refined mechanism for the formal catalytic homo-Nazarov cyclization.

nism, with a rate-limiting cyclopropane ring-opening involving the acid catalyst, followed by fast cyclization and elimination/tautomerization. In the case where the cyclization is too slow, as for example with 33, polymerization or nucleophilic attack becomes favored. Key for the successful development of a catalytic reaction was the adequate stabilization of the different cationic intermediates involved in the reaction, combined with the fast exchange and isomerization rates peculiar to Brønsted acids.

In conclusion, donor-acceptor cyclopropanes have fascinated organic chemists for several decades now. Recently, the use of donor-acceptor cyclopropanes in catalytic methods has been largely focused on their capacity to act as 1,3-dipoles in cycloaddition reactions. Other cyclization reactions using activated cyclopropanes have been less intensively examined and the 
recent development of the formal homoNazarov process by Yadav and co-workers and ourselves have demonstrated that the potential of such reaction is still far from being exhausted. Future important topic of research in the field will certainly be the development of stereoselective versions of the cyclization reactions, as well as their application in the synthesis of more complex bioactive compounds.

Received: February 10, 2009

[1] 'Carbocyclic Three- and Four-Membered Ring Compounds', in 'Houben-Weyl, Methods of Organic Chemistry', Vol. E17a, E17b, E17c, E17d, Thieme Verlag, Stuttgart, 1997.

[2] a) H. U. Reissig, in 'The Chemistry of the Cyclopropyl Group،, Ed. Z. Rappoport, John Wiley \& Sons, Chichester, 1987, pp. 375-443. b) H. N. C. Wong, M. Y. Hon, C. W. Tse, Y. C. Yip, J. Tanko, T. Hudlicky, Chem. Rev. 1989, 89, 165.

[3] a) A. D. Walsh, Nature 1947, 159, 165; b) A. D. Walsh, Nature 1947, 159, 712; c) A. D. Walsh, Trans. Faraday Soc. 1949, 45, 179.

[4] W. A. Bone, W. H. Perkin, J. Chem. Soc. Trans. 1895, 67, 108 .

[5] a) H. U. Reissig, R. Zimmer, Chem. Rev. 2003 , 103, 1151; b) F. Gnad, O. Reiser, Chem. Rev. 2003, 103, 1603 .

[6] E. Wenkert, Acc. Chem. Res. 1980, 13, 27.

[7] a) P. B. Alper, C. Meyers, A. Lerchner, D. R. Siegel, E. M. Carreira, Angew. Chem., Int. Ed. 1999, 38, 3186; b) C. Fischer, C. Meyers, E. M. Carreira, Helv. Chim. Acta 2000, 83, 1175; c) C. Marti, E. M. Carreira, J. Am. Chem. Soc 2005, 127, 11505; d) I. S. Young, M. A. Kerr Angew. Chem., Int. Ed. 2003, 42, 3023; e) I. S Young, M. A. Kerr, Org. Lett. 2004, 6, 139; f) I S. Young, J. L. Williams, M. A. Kerr, Org. Lett 2005, 7, 953; g) C. A. Carson, I. S. Young, M A. Kerr, Synthesis 2008, 485; h) M. Lautens, W. S. Han, J. Am. Chem. Soc. 2002, 124, 6312; i) M. E. Scott, Y. Bethuel, M. Lautens, J. Am.
Chem. Soc. 2007, 129, 1482; j) M. Yu, B. L. Pagenkopf, Org. Lett. 2003, 5, 4639; k) M. Yu, B. L. Pagenkopf, Tetrahedron 2005, 61, 321; 1) B. Bajtos, M. Yu, H. D. Zhao, B. L. Pagenkopf, J. Am. Chem. Soc. 2007, 129, 9631; m) C. L. Morales, B. L. Pagenkopf, Org. Lett. 2008, 10, 157; n) P. D. Pohlhaus, J. S. Johnson, J. Am. Chem. Soc. 2005, 127, 16014; o) R. K. Bowman, J. S. Johnson, Org. Lett. 2006, 8, 573; p) P. D. Pohlhaus, S. D. Sanders, A. T. Parsons, W. Li, J. S. Johnson, J. Am. Chem. Soc. 2008, 130, 8642 ; q) R. P. Wurz, A. B. Charette, Org. Lett. 2005, 7, 2313; r) C. Perreault, S. R. Goudreau, L. E. Zimmer, A. B. Charette, Org. Lett. 2008, 10, 689; s) M. P. Sibi, Z. H. Ma, C. P. Jasperse, J. Am. Chem. Soc. 2005, 127, 5764; t) L. Liu, J. Montgomery, J. Am. Chem. Soc. 2006, 128, 5348; u) Z. G. Zhang, Q. Zhang, S. G. Sun, T. Xiong, Q. Liu, Angew. Chem., Int. Ed. 2007, 46, 1726.

[8] a) G. Stork, M. Marx, J. Am. Chem. Soc. 1969, 91, 2371; b) G. Stork, M. Gregson, J. Am. Chem. Soc. 1969, 91, 2373; c) G. Stork, P. A. Grieco, J. Am. Chem. Soc. 1969, 91, 2407; d) G. Stork, P. A. Grieco, Tetrahedron Lett. 1971, 1807; e) E. J. Corey, R. D. Balanson, Tetrahedron Lett. 1973, 3153; f) S. Danishefsky, J. Dynak, E. Hatch, M. Yamamoto, J. Am. Chem. Soc. 1974, 96, 1256; g) P. A. Grieco, S. Finkelhor, Tetrahedron Lett. 1974, 527. For a review, see: h) S. Danishefsky, Acc. Chem. Res. 1979, 12, 66.

[9] a) A. B. Smith, R. K. Dieter, Tetrahedron 1981 37, 2407; b) A. B. Smith, R. K. Dieter, J. Am. Chem. Soc. 1981, 103, 2017.

[10] a) O. Lifchits, D. Alberico, I. Zakharian, A. B. Charette, J. Org. Chem. 2008, 73, 6838; b) O. Lifchits, A. B. Charette, Org. Lett. 2008, 10, 2809.

[11] a) I. N. Nazarov, I. I. Zaretskaya, Izv. Akad. Nauk. SSSR. Ser. Khim. 1941, 211; b) K. L. Habermas, S. E. Denmark, T. K. Jones, Org. React. (N. Y.) 1994, 45, 1-158.

[12] a) S. Giese, F. G. West, Tetrahedron 2000, 56, 10221; b) Y. Wang, B. D. Schill, A. M. Arif, F. G. West, Org. Lett. 2003, 5, 2747; c) V. K. Aggarwal, A. J. Beffield, Org. Lett. 2003, 5, 5075 ; d) C. Bee, E. Leclerc, M. A. Tius, Org. Lett. 2003, 5, 4927; e) W. He, X. F. Sun, Frontier,
A. J., J. Am. Chem. Soc. 2003, 125, 14278; f) M. Janka, W. He, A. J. Frontier, R. Eisenberg, J. Am. Chem. Soc. 2004, 126, 6864; g) J. A. Malona, J. M. Colbourne, A. J. Frontier, Org. Lett. 2006, 8, 5661; h) W. He, I. R. Herrick, T. A. Atesin, P. A. Caruana, C. A. Kellenberger, A. J. Frontier, J. Am. Chem. Soc. 2008, 130, 1003; i) G. X. Liang, S. N. Gradl, D. Trauner, Org. Lett. 2003, 5, 4931; j) G. X. Liang, D. Trauner, J. Am. Chem. Soc. 2004, 126, 9544; k) I. Walz, A. Bertogg, A. Togni, Eur. J. Org. Chem. 2007, 2650; 1) I. Walz, A. Togni, Chem. Commun. 2008, 4315; m) M. Rueping, W. Ieawsuwan, A. P. Antonchick, B. J. Nachtsheim, Angew. Chem., Int. Ed. 2007, 46, 2097; n) M. Amere, J. Blanchet, M. C. Lasne, J. Rouden, Tetrahedron Lett. 2008, 49, 2541. For reviews, see: o) M. A. Tius, Eur. J. Org. Chem. 2005, 2193; p) A. J. Frontier, C. Collison, Tetrahedron 2005, 61, 7577; q) H. Pellissier, Tetrahedron 2005, 61, 6479.

[13] O. Tsuge, S. Kanemasa, T. Otsuka, T. Suzuki, Bull. Chem. Soc. Jpn. 1988, 61, 2897.

[14] a) W. S. Murphy, S. Wattanasin, Tetrahedron Lett. 1980, 21, 1887; b) W. S. Murphy, S. Wattanasin, J. Chem. Soc. Perkin Trans. 1 1981, 2920; c) W. S. Murphy, S. Wattanasin, J. Chem. Soc. Perkin Trans. 1 1982, 271; d) W. S. Murphy, S. Wattanasin, J. Chem. Soc. Perkin Trans. 1 1982, 1029; e) L. Greiner-Bechert, T. Sprang, H. H. Otto, Mon. Chem. 2005, 136, 635; f) V. K. Yadav, N. V. Kumar, Chem. Commun. 2008, 3774.

[15] a) V. K. Yadav, N. V. Kumar, J. Am. Chem Soc. 2004, 126, 8652; b) V. K. Yadav, V. Sriramurthy, Angew. Chem., Int. Ed. 2004, 43, 2669; c) D. Agrawal, V. K. Yadav, Chem. Commun. 2008, 6471.

[16] F. De Simone, J. Andres, R. Torosantucci, J. Waser, Org. Lett. 2009, 11, 1023.

[17] S. E. Denmark, R. C. Klix, Tetrahedron 1988 $44,4043$. 